\title{
Por um consumo sustentável: reflexões sobre agroecologia e agricultura no contexto urbano
}

\author{
Giovana Goretti Feijó de Almeida ${ }^{1}$ \\ Vonia Engel ${ }^{2}$
}

\begin{abstract}
Resumo
O objetivo deste artigo é o de discutir a presença da agroecologia nos mercados sustentáveis por meio das fazendas e da agricultura urbanas. Busca-se um repensar sobre o espaço urbano, sendo utilizado com elementos do espaço rural e na interação entre esses espaços, que, muitas vezes, são vistos dicotomicamente. Utilizar-se-á a perspectiva teórica de Caporal e Costabeber (2004), a agroecologia como ciência que estabelece relações complexas com o agroecossistema e também a compreensão de Assis e Romeiro (2002), os quais relacionam a agroecologia com práticas mais sustentáveis de intervenção no meio ambiente. A partir dessa reflexão, portanto, adota-se o estudo de caso da fazenda urbana nova iorquina, Brooklyn Grange, divulgada na mídia como a maior fazenda urbana do mundo. O estudo é de natureza qualitativa, de cunho exploratório, com coleta de dados no site da fazenda citada. Os resultados apontam para um novo pensamento sobre o rural, no qual a busca por uma melhor qualidade de vida é um estilo que vem ganhando cada vez mais adeptos, tendo a agroecologia um papel estratégico nesse movimento entre rural e urbano.
\end{abstract}

Palavras-chave: Sustentabilidade. Consumo. Agroecologia. Agricultura Urbana. Fazendas Urbanas.

\begin{abstract}
The objective of this paper is to discuss the presence of agroecology in sustainable markets through urban farms and agriculture. It seeks to rethink about the urban space, being used with elements of the rural space and in the interaction between these spaces that, often, are seen dichotomically. It will be used of the theoretical perspective of Caporal and Costabeber (2004) of the agroecology as science that establishes complex relationships with the agroecosystem and also Assis and Romeiro (2002) understanding that relate the agroecology with more maintainable practices of intervention in the environment. Begin from this reflection, therefore, it is adopted the study of case of the farm from New York, Brooklyn Grange. The study is of qualitative nature, I coin exploratory with collection of data in the site of the mentioned farm. The results appear for a new thought on the rural, in which the search for a better life quality is a style that is winning followers more and more, tends the agroecology a strategic paper in that movement between rural and urban.
\end{abstract}

Keywords: Sustainability. Consumption. Agroecology. Urban Agriculture. Urban Farms.

\section{Introdução}

O objetivo deste artigo é o de discutir a presença da agroecologia nos mercados sustentáveis por meio das fazendas e da agricultura urbanas, já consolidadas em vários

\footnotetext{
1 Doutoranda em Desenvolvimento Regional. Pesquisadora-membro do Observatório do Desenvolvimento Regional. goretti.giovana@gmail.com

${ }^{2}$ Doutoranda no Programa de Pós-Graduação em Desenvolvimento Regional (PPGDR-UNISC). Pesquisadora do Observatório do Desenvolvimento Regional. jopec@fahor.com.br
} 
lugares do mundo. No Brasil, o formato é um pouco diferente, pois não há fazendas urbanas, mas hortas urbanas ou hortas comunitárias. Adotou-se o caso dos Estados Unidos pela sua configuração de fazenda no contexto urbano. Assim, pode-se discutir a questão da agroecologia inserida no ambiente da cidade, tendo suas práticas ancoradas na demanda de novos mercados sustentáveis.

Dois discursos que circulam na mídia incentivam a criação das fazendas urbanas. $\mathrm{O}$ primeiro sustenta-se na falta de alimentos a partir de 2050 (FAO, 2015a), devido ao aumento significativo da população mundial. Nesse sentido, a mídia intensifica essa projeção e deixa preocupada a população, que espera que o poder público ou a tecnologia resolvam esse problema. O segundo discurso diz respeito à crescente urbanização que invade o espaço rural e ao próprio êxodo rural (FAO, 2015a). Dessa forma, não haveria espaço e nem pessoas para produzirem alimentos suficientes à alimentação da população do mundo. Urbano e rural se posicionam, neste caso, em um cabo de guerra, no qual ambos não se complementam, mas se contrastam.

Busca-se, também, com este estudo, um repensar sobre o espaço urbano sendo utilizado com elementos do espaço rural, e ainda na interação entre esses espaços que, muitas vezes, são vistos dicotomicamente. O intuito não é o de separar campo e cidade, ou rural e urbano, mas o de compreender suas interações na contemporaneidade. Vive-se um momento que Sposito (2006) denomina como binômio urbano/rural, em que não se consegue distinguir onde acaba um e começa o outro, devido às suas relações, que se intensificam, tornando seus limites imprecisos, ao mesmo tempo em que esses espaços se sobrepõem. A agroecologia, antes presente apenas no espaço rural, é um dos elementos sobrepostos que surge no meio urbano, estando ainda presente nos novos mercados centrados na sustentabilidade.

Este estudo utiliza a perspectiva teórica de Caporal e Costabeber (2004), que considera a agroecologia uma ciência ancorada em bases sustentáveis, que vai além do uso de insumos químicos, diferindo também da produção de produtos orgânicos, que estariam, segundo Assis e Romeiro (2002), mais relacionados à prática agrícola, adaptada a um contexto social que segue uma lógica capitalista, voltada a atender às expectativas do consumidor. Já o contexto da agroecologia como nova agricultura presente em mercados sustentáveis ancora-se na visão de Niederle, Almeida e Vezzani (2013), que analisam as 
dinâmicas envolvidas na construção social de mercados e no estabelecimento de novas relações entre produção (produtor) e consumo (consumidor).

Assim sendo, questiona-se de que forma a agroecologia está inserida nesses novos mercados sustentáveis e como se pode pensar nas práticas da agroecologia no contexto urbano. Neste panorama que se apresenta, outras questões emergem: as fazendas urbanas utilizam o mesmo formato do rural, ou seja, formas de plantio, agrotóxicos, mesmas preocupações, entre outros? A agroecologia é utilizada na perspectiva de uma melhor qualidade de vida ou na perspectiva de um melhor e mais rentável negócio? Rentável para quem? Em que medida os espaços rural e urbano interagem um com o outro sem interferirem em seus contextos? Há um mercado da sustentabilidade? É mais interessante ter um conceito claro e transparente sobre agroecologia, ou manter a agroecologia associada a interpretações difusas? Busca-se responder a essas questões e elucidá-las, ancorando as respostas na visão dos autores Caporal e Costabeber (2004) e Assis e Romeiro (2002), discutindo-as ao longo do texto.

A partir dessas reflexões, portanto, adota-se o caso da fazenda urbana nova iorquina, Brooklyn Grange, que se posiciona na mídia como sendo uma das maiores do mundo ${ }^{3}$. 0 estudo é de natureza qualitativa, de cunho exploratório, com coleta de dados primários no site da fazenda citada. A metodologia ainda compreendeu o levantamento teórico em livros, artigos e sites, obtendo-se, assim, os dados secundários sobre o tema da agroecologia.

Pretendeu-se abordar a discussão sobre o uso da agroecologia tanto no meio urbano como no rural, bem como seu uso nos mercados sustentáveis. Discutiu-se a dicotomia entre rural e urbano como espaços antagônicos e complementares, e como eles têm se tornado, progressivamente, na contemporaneidade, espaços sobrepostos. Foi abordado ainda o conceito de agroecologia como uma opção de sustentabilidade à agricultura praticada nas cidades. Este levantamento de dados e informações busca auxiliar na compreensão da utilização de fazendas no uso do espaço urbano, dentro das cidades, podendo ainda servir de base para novas pesquisas e discussões sobre a temática proposta.

Faz-se uma reflexão acerca dos mercados sustentáveis, que utilizam o discurso da agroecologia para se consolidarem mais facilmente no contexto da agricultura urbana.

\footnotetext{
${ }^{3}$ Essas informações são com base no site da Brooklyn Grange e no próprio posicionamento que eles têm frente ao mercado.
} 
Procura-se demonstrar que os espaços rurais e urbanos estão sobrepostos, embora cada um tenha suas características específicas. A agricultura urbana reforça, cada vez mais, essa lógica de sobreposição, e o uso da nomenclatura da agroecologia urbana abre e consolida novos mercados sustentáveis, como o das fazendas urbanas. Colocam-se, então, várias questões relativas a essa forma urbana de produção de alimentos e como pode afetar a própria prática da agroecologia.

\section{0 rural, o urbano e a agroecologia em um contexto urbano}

A literatura construiu a relação lógica dicotômica entre rural e urbano, porém, na contemporaneidade, essa estrutura não irá se sustentar por muito mais tempo. Cada vez mais, o urbano faz parte do meio rural, e o meio rural faz parte da cidade. Há uma integração invisível entre esses dois espaços, que permite uma sobreposição entre ambos e um entendimento de suas complementaridades, tendo a agroecologia um papel estratégico no contexto desses ambientes.

\footnotetext{
No contexto da agroecologia, são comuns interpretações equivocadas sobre o assunto. Expressões como: 'existe mercado para a Agroecologia'; 'a Agroecologia produz tanto quanto a agricultura convenciona'; 'a Agroecologia é menos rentável que a agricultura convencional'; 'a Agroecologia é um novo modelo tecnológico'; 'agora, a Agroecologia é uma política pública'; 'vamos fazer uma feira de Agroecologia'; dentre outras, não tratam a agroecologia com um enfoque científico, reduzindo seu significado mais amplo e mascarando sua potencialidade para apoiar processos de desenvolvimento rural sustentável (CAPORAL; COSTABEBER, 2004, p. 7).
}

Já na perspectiva de Candiotto, Carrijo e Oliveira (2008), as práticas ecológicas estão inseridas na corrente da agricultura orgânica, que, por sua vez, está inserida na da agricultura alternativa. Possuem singularidades que as tornam mais específicas do que a agricultura orgânica, e, por esse motivo, não se pode igualá-la com a agroecologia relacionada à diversidade, ao autoconsumo e às práticas agrícolas e socioculturais que não seguem a lógica do capital e nem a demanda particular do mercado. A agroecologia dita suas regras, no seu tempo, podendo o mercado se adequar ou não a ela, todavia o contrário não se aplica. Neste sentido, Caporal e Costabeber (2004) salientam que ela é mais ampla e leva em conta as relações socioeconômicas, mas procura compreender o agroecossistema de 
forma conjunta com as relações entre seres humanos, animais, plantas e o uso do solo. Nada é utilizado sem a compreensão dessas relações.

A agroecologia é uma ciência desenvolvida a partir da década de 1970, como consequência de uma busca de suporte teórico para as diferentes correntes de agricultura alternativa que já vinham se desenvolvendo desde a década de 1920. Surge como resposta aos críticos desses movimentos por uma nova agricultura, integrada ao meio ambiente, definida como uma tentativa retrógrada de volta ao passado na agricultura (ROMEIRO; ASSIS, 2002, p. 67). Isso posto, reforça-se que com essa visão, o meio rural é percebido como atrasado em relação ao urbano, distanciando cada vez mais um do outro.

A agroecologia é vista "[...] como ciência que estabelece as bases para a construção de estilos de agriculturas sustentáveis e de estratégias de desenvolvimento rural sustentável" (CAPORAL; COSTABEBER, 2004, p. 6-7). Dessa forma, a variável sustentabilidade se insere no conceito da agroecologia, tendo um papel de extrema relevância em seu contexto. Contudo, agroecologia difere de nomenclaturas como produção orgânica. Para Assis e Romeiro (2002), a agricultura orgânica está voltada para uma prática agrícola com características técnicas adequadas ao contexto social no qual se insere, seguindo inclusive uma lógica capitalista voltada para o mercado. Embora esse tipo de produção tenha o intuito de produzir alimentos sem a utilização de insumos químicos, atende às necessidades e expectativas de demandas dos consumidores. Os autores ainda reforçam que essa pressão do mercado beneficia a produção com base em altas tecnologias, e, ao mesmo tempo, ameaça a sustentabilidade, visto que não considera o equilíbrio em relação aos aspectos social, econômico e ecológico.

Já a agroecologia segue uma corrente que vai além do uso - ou não - de agrotóxicos na produção de alimentos gerados por uma demanda de mercado. Sua relação é mais com uma ciência que busca o manejo adequado dos recursos naturais, reduzindo os impactos ambiental, social e econômico. Dessa forma, percebe-se que a agroecologia não interfere apenas na questão da sustentabilidade como uma demanda de mercado. Conforme Caporal e Costabeber (2004, p. 5), a agroecologia busca “[...] impulsionar uma mudança substancial no meio rural e na agricultura [...] numa perspectiva que assegure a sustentabilidade socioambiental e econômica dos territórios rurais". Portanto, é muito mais do que produzir alimentos saudáveis, pois possui toda uma metodologia fundamentada por essa prática. 
Embora sempre haja, de alguma forma, impactos negativos em toda forma de interferência no meio ambiente, a agroecologia e a produção orgânica possuem impactos muito menores se comparados aos da monocultura mecanizada que, em sua maioria, é voltada ao mercado de exportação. Assim, “[...] quando se fala de agricultura sustentável, se está falando de estilos de agricultura de base ecológica que atendam a requisitos de solidariedade entre as gerações atuais e destas para com as futuras gerações, o que alguns autores chamam de uma "ética da solidariedade'" (CAPORAL; COSTABEBER, 2004, p. 16). Portanto, a agroecologia tem uma preocupação muito maior com a sustentabilidade ambiental do que com os demais modos de produção agrícola da contemporaneidade, e este é um dos motivos que a diferenciam dos demais.

Tanto Caporal e Costabeber (2004) quanto Assis e Romeiro (2002) relacionam a agroecologia com as melhores práticas de intervir no meio ambiente, aplicando conhecimentos técnicos e também científicos (antigos e modernos), no intuito de resgatar esses conhecimentos que a agricultura convencional, voltada ao atendimento de uma demanda crescente do mercado, desconsidera. No entanto, percebe-se que a agroecologia, mesmo tendo essa preocupação, pode e utiliza inovações tecnológicas para gerar desenvolvimento em agroecossistemas sustentáveis, tendo o cuidado de gerar o menor impacto possível à natureza.

Partindo do referencial teórico exposto, verifica-se que a agroecologia tem uma grande preocupação com as futuras gerações, para que estas tenham condições de também aproveitar os recursos naturais disponíveis na contemporaneidade. Concomitantemente, é interessante para o mercado e, principalmente, para os novos mercados sustentáveis que o conceito de agroecologia permaneça difuso.

\section{Mercados sustentáveis e os discursos da sustentabilidade}

Os mercados ou os nichos de mercados, muitas vezes, são criados a partir de uma demanda do próprio consumidor. Quando isto acontece, há uma relação intrínseca entre mercados e consumidores. A partir do momento (mais especificamente na década de 1970, na qual houve uma intensificação do processo de urbanização e de industrialização) em que as pessoas começam a refletir mais sobre o impacto do consumo no meio ambiente, começa também a surgir um mercado que visa atender a este consumidor, chamado de 
ecologicamente correto, consumidor verde, entre tantas outras nomenclaturas. Salienta-se que a intensificação da atitude sobre o impacto do consumo ocorreu a partir da Rio 1992 e da Rio+20. Já no período de 1970, intensificaram-se a urbanização e a criação de indústrias, fazendo com que as pessoas se deslocassem do rural para o urbano. A forma como as pessoas consomem e levam esse estilo de vida em particular é chamada de consumo sustentável (BEDANTE, 2004). Assim sendo, se há mercado e demanda, haverá igualmente propostas e soluções para atender a esse nicho específico.

Contudo, quando se faz referência a consumo ou a mercados sustentáveis, é importante ressaltar que há também uma lógica de raciocínio econômico que perpassa por esses contextos. Segundo Tachizawa (2010), essa postura interage mais com organizações que tenham uma boa imagem institucional no mercado, atuando de forma ecologicamente responsável, e que buscam certo retorno além do econômico. É importante refletir sobre o que seriam os mercados sustentáveis. De forma abrangente, faz parte dos negócios empresariais a disputa por nichos de mercado. Com o atual panorama da sustentabilidade ambiental, e devido à crise que o planeta vem sofrendo, pelo uso inadequado de recursos naturais (MUELLER, 2007), tem se intensificado o apelo a um nicho em especial, o dos mercados sustentáveis. Em outras palavras, seriam mercados que têm como apelo primordial a preservação do meio ambiente.

[...] é possível dizer que a imagem central do conceito de produtos ecologicamente corretos está ligada à 'preservação do meio ambiente', à 'reciclagem', à ideia de 'produtos sem agrotóxicos', de 'produtos saudáveis', da 'sustentabilidade', do 'bem-estar' e ligada à preocupação com o 'meio ambiente e natureza' e com um 'futuro melhor' (DE TONI, 2013, p. 185).

As empresas que fazem parte desses mercados "ecologicamente sustentáveis" têm seus discursos ancorados, principalmente, em critérios de melhor qualidade de vida e de responsabilidade socioambiental. Evidentemente, por se tratar de mercados, há uma lógica capitalista em jogo, assim como a inserção de múltiplas dimensões do processo da globalização. Percebe-se que as estratégias das empresas, cada vez mais se complexificam, mesmo que sua diretriz principal seja a busca pelo lucro. No caso da competitividade empresarial, há uma lógica implícita: preservar o meio ambiente, porém gerando lucratividade. 
Nesse sentido, há vários nichos que já estão consolidados nesse mercado que se autodenomina sustentável. Entre eles estão o turismo rural, os ecoprodutos, os produtos verdes, a sustentabilidade das empresas, os selos verdes, entre outros. Esse ambiente não se preocupa apenas com os recursos naturais, há outros apelos que o constituem, como, por exemplo, o discurso da falta de alimentos em um futuro próximo. Há duas correntes que abordam essa questão.

Uma é a de que, em 2050, o mundo não conseguirá mais produzir alimentos, visto que haverá um aumento muito grande na população, tornando inviável alimentar a todos. Outro diz que já há, na contemporaneidade, alimentos para toda a população. Essa discussão leva ao seguinte questionamento: se há alimentos, então por que ainda há fome no mundo (FAO, 2015a)? A partir dos estudos da ONU para a Alimentação e a Agricultura, algumas alternativas vêm surgindo, entre elas, os telhados verdes, a agroecologia e a agricultura urbana, como formas de enfrentamento da questão de falta de alimentos e também como oportunidade para novos mercados sustentáveis, aspectos estes que serão retratados na sequência.

\section{De telhados verdes à agricultura urbana}

Uma das soluções encontradas pelo homem na contemporaneidade em relação ao uso dos espaços urbanos foi a utilização das coberturas de casas e de prédios para a implantação dos chamados telhados verdes. São novos usos para esses espaços que, como consequência, podem trazer o cuidado com a preservação de recursos naturais. Os telhados verdes são utilizados amplamente na Europa e América do Norte, porém, no Brasil, o fenômeno ainda é recente. O telhado verde, também chamado de telhado vivo, telhado ecológico, ecotelhado, biocobertura, ou outros termos que se apresentam, é uma espécie de jardim suspenso que, com uma satisfatória relação custo-benefício, incorpora vegetação ornamental à cobertura de casas, edifícios, quiosques ou lajes.

Alguns dos benefícios dessa opção sustentável é a diminuição do aquecimento global, funcionando como um isolante térmico, reduzindo até $70 \%$ do calor e economizando na conta da energia elétrica. Tudo isso sem mencionar a valorização do imóvel e o uso de um espaço até então sem utilidade, como para um jardim, por exemplo. 
Os telhados verdes vêm sendo construídos há milhares de anos. Desde a antiga Babilônia à arquitetura tradicional, na Escandinávia, a mesma lógica vem sendo empregada para aliar estética visual e qualidade ambiental às construções e ao ambiente urbano. A partir da década de 1960, na Alemanha, a nova indústria de telhados verdes pesquisou e aperfeiçoou materiais, desenvolveu normas e manuais construtivos, pesquisando os benefícios ambientais, sociais e econômicos deste novo mercado - são os chamados telhados verdes modernos. A prática dos últimos 35 anos demonstrou que é possível desenvolver sistemas de cultivo seguros e aplicáveis a qualquer tipo de construção, possibilitando a conversão de cidades inteiras para o novo conceito de cidades verdes - em um curto espaço de tempo. Hoje o conceito moderno de telhados verdes pode ser considerado uma tendência mundial, com experiências sendo desenvolvidas em todas as grandes cidades do mundo. Pode-se dizer que há um movimento global para disseminação de telhados verdes, visando a adaptação urbana às novas condições de mudanças do clima impostas pelo aquecimento global (INSTITUTO CIDADE JARDIM, 2015).

Entretanto, ainda é restrita a implementação do telhado verde no Brasil pela grande maioria da população, devido ao seu alto custo de instalação e manutenção. Segundo o Conselho Brasileiro de Construção Sustentável ${ }^{4}$ - CBCS (2015), “[...] atualmente há um número restrito de empresas e profissionais capacitados para executar os telhados verdes e um número ainda menor de fornecedores de componentes para sua construção". Justificase, dessa forma, o uso dos telhados verdes (para jardins e até mesmo para parques) por quem tem recursos econômicos de implementá-los, principalmente, as grandes empresas e o poder público.

De acordo com o Instituto Cidade $\operatorname{Jardim}^{5}$ (2015), os telhados verdes são "[...] sistemas desenhados para permitir o cultivo eficiente de vegetação sobre o topo de uma construção, com objetivo de melhorar seu desempenho econômico e ambiental". Por essa lógica, estes telhados podem abranger desde um gramado a um jardim, um parque a uma praça, até mesmo em um espaço como o espaço rural. Assim, a utilização desses espaços tem ultrapassado o uso como jardins ou até mesmo parques públicos (como é o caso do município de Recife, no Brasil), passando de um caráter estético e de apelo ao meio ambiente, para um caráter produtivo e como uma alternativa ao meio rural. É o caso do uso desses telhados e até mesmo de prédios inteiros, construídos para abranger a agricultura urbana.

\footnotetext{
${ }^{4}$ O Conselho Brasileiro de Construção Sustentável (CBCS) é uma OSCIP (Organização da Sociedade Civil de Interesse Público), de âmbito nacional, criada em agosto de 2007, como resultado da articulação entre lideranças empresariais, pesquisadores, consultores, profissionais atuantes e formadores de opinião.

${ }^{5}$ Fundado em 2008 pela ecóloga Fabiana Scarda e pelo engenheiro agrônomo Sérgio Rocha, o Instituto Cidade Jardim é uma das primeiras empresas brasileiras especializadas na pesquisa e desenvolvimento de tecnologias para telhados verdes e jardins suspensos.
} 
Quando o assunto é agricultura, mesmo que no espaço urbano, há inúmeras questões que demandam uma reflexão maior. Quem está por trás da ideia das fazendas urbanas e das hortas urbanas? São os agricultores familiares? Os grandes fazendeiros? Quem são os atores destas fazendas e hortas no contexto urbano? Estaria o espaço urbano reduzindo o meio rural a tal ponto que precise haver um movimento contrário, ou seja, os elementos do meio rural (como a produção em diversas escalas) invadindo o meio urbano? Dessa forma, então, não haverá mais esta dicotomia entre rural e urbano? Outra questão diz respeito aos atores deste novo meio híbrido entre rural e urbano: Será que vai surgir uma nova denominação de agricultor a partir da agricultura urbana? Talvez um agricultor urbano ou um agricultor urbano-rural? A agricultura urbana é oriunda de quem? Percebe-se que todos estes questionamentos são oriundos do conceito de agricultura rural em um contexto urbano, no qual dois meios se complementam e se sobrepõem ao mesmo tempo.

Segundo a Fundação de Agricultura Urbana (RUAF, 2015), a principal diferença entre a agricultura rural convencional e a agricultura urbana é a integração da agricultura urbana ao sistema econômico e ecológico urbano, também denominado de ecossistema urbano. Os determinantes principais, segundo Mougeot (2005), dessa agricultura das cidades são os tipos de atividade econômica; a localização intraurbana ou periurbana; os tipos de áreas onde ela é praticada; sua escala e sistema de produção; as categorias e subcategorias de produtos (alimentícios e não alimentícios); e a destinação dos produtos, inclusive sua comercialização.

\footnotetext{
O princípio da integração da agricultura no ecossistema urbano nos permite reconhecer três tipos de situações ou relações, conforme o grau de integração da agricultura que se pratica na cidade com o 'organismo' urbano, em geral. A primeira relação é que, em qualquer cidade e em qualquer momento, seus alimentos são produzidos por uma agricultura que é de caráter rural, periurbano e intraurbano, pois as três interagem e se complementam mutuamente em variados graus. A segunda relação é que, em qualquer momento, em cidades de diferentes tamanhos ou complexidade, a agricultura nelas praticada será mais do tipo urbano (mais intensiva e produtiva) nos centros maiores do que nos menores. A terceira relação é que, em qualquer cidade, em determinado período de tempo, durante o processo de urbanização, a agricultura de tipo urbano e intensivo crescerá como porcentagem de toda a agricultura praticada na referida cidade. Em todas as três relações, a agricultura se tornará mais urbana, ou seja, mais integrada ao ecossistema urbano, por meio de vários processos que se acumulam no tempo e que são mais numerosos e efetivos nos grandes centros urbanos (MOUGEOT, 2005).
} 
Este tipo de agricultura praticado nas cidades, em vez de no meio rural, tem influenciado inclusive as políticas nacionais e locais, como, por exemplo, nos países da América Latina e no Caribe (FAO, 2015b). No Brasil, essa influência ainda dá os primeiros passos. Para a RUAF (2015), “[...] a agricultura urbana pode ser definida brevemente, como o cultivo de plantas e a criação de animais dentro e ao redor das cidades". Nesta perspectiva, a agricultura urbana interage com o próprio desenvolvimento urbano, podendo contribuir na diversificação e na criação de estratégias de planejamento das cidades, ou, até mesmo, intensificar os problemas já existentes. Também pode vir a ser uma alternativa para se (re)utilizar espaços urbanos vazios, cooperando com a estética das cidades numa melhor preservação de recursos ambientais.

\section{Fazendas e hortas urbanas: a produção rural na cidade}

A agricultura urbana inclui atividades de produção agrícola, porém no espaço das cidades. Além disso, também estão inseridas as atividades de transformação e comercialização, insumos (compostagem) e prestação de serviços por microempresas ou ONGs, dentre outras.

Neste tipo de agricultura que se desenvolve em um ambiente urbano, relacionam-se, mais intimamente, a produção e o marketing, em termos de tempo e espaço, do que na agricultura rural, graças a uma maior proximidade geográfica e ao fluxo de recursos mais rápido, ou seja, a logística da agricultura urbana é mais estratégica do que a da agricultura rural, reduzindo e até mesmo eliminando determinadas variáveis, como, por exemplo, as distâncias (RUAF, 2015), independentemente do tamanho da cidade ou da sua densidade. Este vínculo com os espaços rural e urbano evidencia a agroecologia e suas práticas mais sustentáveis de intervenção no meio ambiente (ASSIS e ROMEIRO, 2002), estabelecendo também relações complexas com o agroecossistema (CAPORAL; COSTABEBER, 2004), ao mesmo tempo em que cria consumidores mais conscientes no uso dos recursos naturais e também novos mercados sustentáveis. 
[...] a agricultura urbana é a praticada dentro (intraurbana) ou na periferia (periurbana) dos centros urbanos (sejam eles pequenas localidades, cidades ou até megalópolis), onde cultiva, produz, cria, processa e distribui uma variedade de produtos alimentícios e não alimentícios, (re)utiliza largamente os recursos humanos e materiais e os produtos e serviços encontrados dentro e em torno da área urbana, e, por sua vez, oferece recursos humanos e materiais, produtos e serviços para essa mesma área urbana (MOUGEOT, 2015).

Segundo a RUAF (2015), a produção agrícola urbana é geralmente destinada mais para o autoconsumo, encaminhando seus excedentes às negociações de mercado. A agricultura urbana, orientada para o mercado, pode demandar grande ou pequeno volume de produção com alto valor econômico agregado, como se verá no caso da fazenda urbana nova iorquina, objeto empírico deste estudo.

Na contemporaneidade, há vários suportes que atendem ao mercado da agricultura urbana. Na Europa, as fazendas urbanas ou os telhados verdes são oriundos de políticas públicas e recebem, em diversos casos, isenção fiscal para sua prática. No Brasil, o fenômeno dos telhados verdes ainda é recente, começando com dois Projetos de Lei ${ }^{6}$ e tendo uma Lei Municipal $^{7}$ aprovada em abril de 2015. No entanto, considerando as dimensões territoriais brasileiras ainda são poucos os municípios brasileiros implementando leis que estimulam o uso destes espaços urbanos vazios. No entanto, muitos prédios ou até mesmo residências têm utilizado esse formato devido aos seus benefícios e, principalmente, para reduzirem o impacto ao meio ambiente.

Os restaurantes também têm aplicado este formato para restringir seus custos e logística, além de agregar valor aos produtos oferecidos. Nesse sentido, o marketing tem um papel central (KOTLER, 1998; COBRA, 1992; GIGLIO, 1996). Um ponto que chama a atenção é o valor agregado dos produtos orgânicos e sustentáveis, já que eles têm um valor mais elevado em relação ao industrializados, e acabam sendo consumidos por uma parcela pequena da população, aquela de maior poder aquisitivo, que tem condições financeiras de consumi-los.

Percebe-se que, quando se aborda o tema agricultura urbana, surgem posições variadas em relação ao assunto. Durante a pesquisa, foi observado que, em vários dados secundários, coletados para esta pesquisa, não há menção aos tipos de fazendas urbanas.

\footnotetext{
${ }^{6}$ Projeto de Lei no 1.703 , de 2011 e o Projeto de Lei no 067/2013.

${ }^{7}$ Aprovada em abril de 2015, a Lei Municipal no 18.112/2015, em Recife, prevê o plantio de gramas, hortaliças, arbustos, arbusto e árvores de pequeno porte nas lajes dos edifícios.
} 
Contudo, de forma abrangente, podem-se elencar três formatos que foram mencionados nas mídias: 1 ) a que utiliza os telhados dos prédios (as primeiras que surgiram eram somente nessa configuração horizontal), 2) a que utiliza toda a estrutura de um prédio (chamada de fazenda vertical) e, 3) aquelas que são estufas em containers (chamadas de fazendas pop-up de containers). Enquanto nos demais países, a prática das fazendas urbanas (tanto em telhados como em prédios totalmente dedicados à agricultura urbana) é mais frequente, no Brasil se percebe mais o contexto das hortas urbanas nos telhados dos prédios (RUAF, 2015).

Salienta-se que este estudo teve como foco a agricultura das fazendas urbanas. 0 intuito é o de refletir sobre este formato de agricultura presente nas cidades e também ponderar sobre seus atores sociais e o reaproveitamento dos espaços urbanos vazios, assim como o uso estratégico da agroecologia em novos mercados sustentáveis. Na sequência, será analisado o estudo de caso de uma fazenda nova iorquina que utiliza essa estratégia.

\section{Brooklyn Grange Farm: as fazendas no contexto urbano}

Considerada pela mídia como a maior fazenda urbana do mundo, a Brooklyn Grange Farm, localizada em Nova York, nos Estados Unidos, não é uma, mas duas fazendas instaladas em dois telhados verdes inseridos no contexto da agricultura urbana. Sua produção agrícola é em torno de 50 mil libras de vegetais cultivados organicamente por ano, em 2,5 acres "de telhados". Também contempla um aviário com galinhas poedeiras e um apiário comercial com mais de trinta colmeias de abelhas em plena cidade nova iorquina. Vendem seus produtos para restaurantes e diretamente para o público em geral, através de farmstands semanais (feiras), enfatizando seu posicionamento sustentável por meio do marketing centrado em uma demanda orgânica e na preocupação com os recursos naturais do planeta (BROOKLYN GRANGE, 2016).

A Broklyn Grange Farm é composta das seguintes fazendas urbanas: 1) a Brooklyn Navy Yard Farm, (Brooklyn, NY) e, 2) da Flagship Farm (Long Island City, NY). A Brooklyn Navy Yard (FIGURA 1) surgiu devido ao apoio do Departamento de Proteção Ambiental. Foi firmado um contrato por dez anos com a Broklyn Grange (Figura 2) e outro de 20 anos com a Brooklyn Navy Yard, duas fazendas que, juntas, formam a maior fazenda urbana do mundo. Dessa forma, arrendar telhados em Nova York também se revela uma oportunidade de 
negócio rentável, que contempla dois nichos de mercados: um é o da sustentabilidade, e outro, da reutilização de espaços vazios urbanos. A imagem que a Broklyn Grange Farm constrói e fortalece no mercado, assim como o posicionamento que estabelece, a visão de Tachizawa (2010) de que as organizações devem ter uma boa imagem institucional, para atuarem nos mercados, principalmente nos sustentáveis. Essa construção é também uma estratégia de marketing que segue uma lógica capitalista, orientada para um nicho de mercado, o da sustentabilidade ambiental.

\section{Figura 1 - Brooklyn Navy Yard Farm}

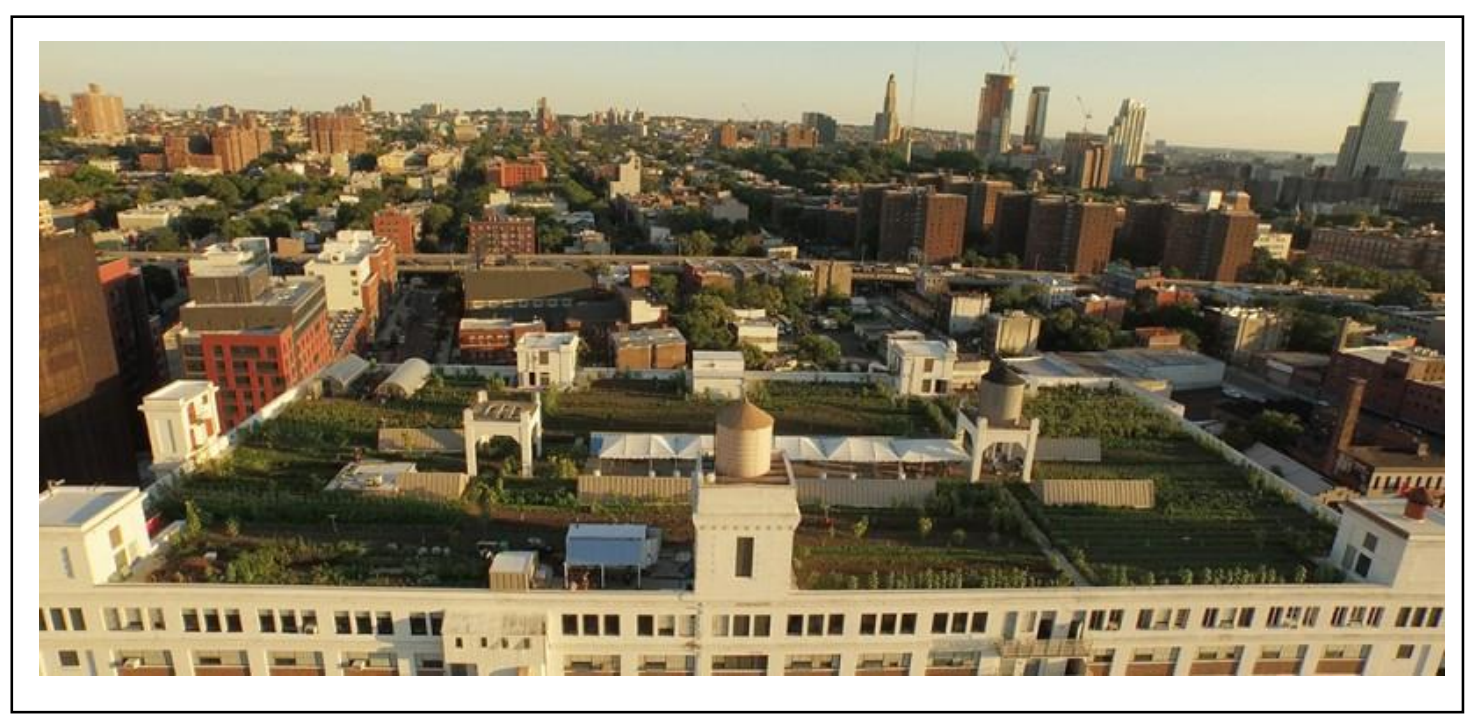

Fonte: Brooklyn Grange (2016).

Segundo o site da Brooklyn Grange, além da agricultura urbana, há o fornecimento de "[...] consultoria para telhados verdes e instalação de serviços verdes para clientes no mundo inteiro", e, também, para "[...] inúmeras organizações sem fins lucrativos em toda a Nova York, no intuito de promover comunidades locais fortes e saudáveis". Não menciona declaradamente quais as inúmeras organizações sem fins lucrativos que atende, nem como promove as comunidades locais. Sustentar também que atende a clientes no mundo inteiro é um argumento muito ousado. À vista disso, constata-se que essas alegações são muito mais argumentos de venda, ancorados em um marketing que trabalha fortemente a imagem dessa fazenda urbana. 
Figura 2 - Flagship Farm

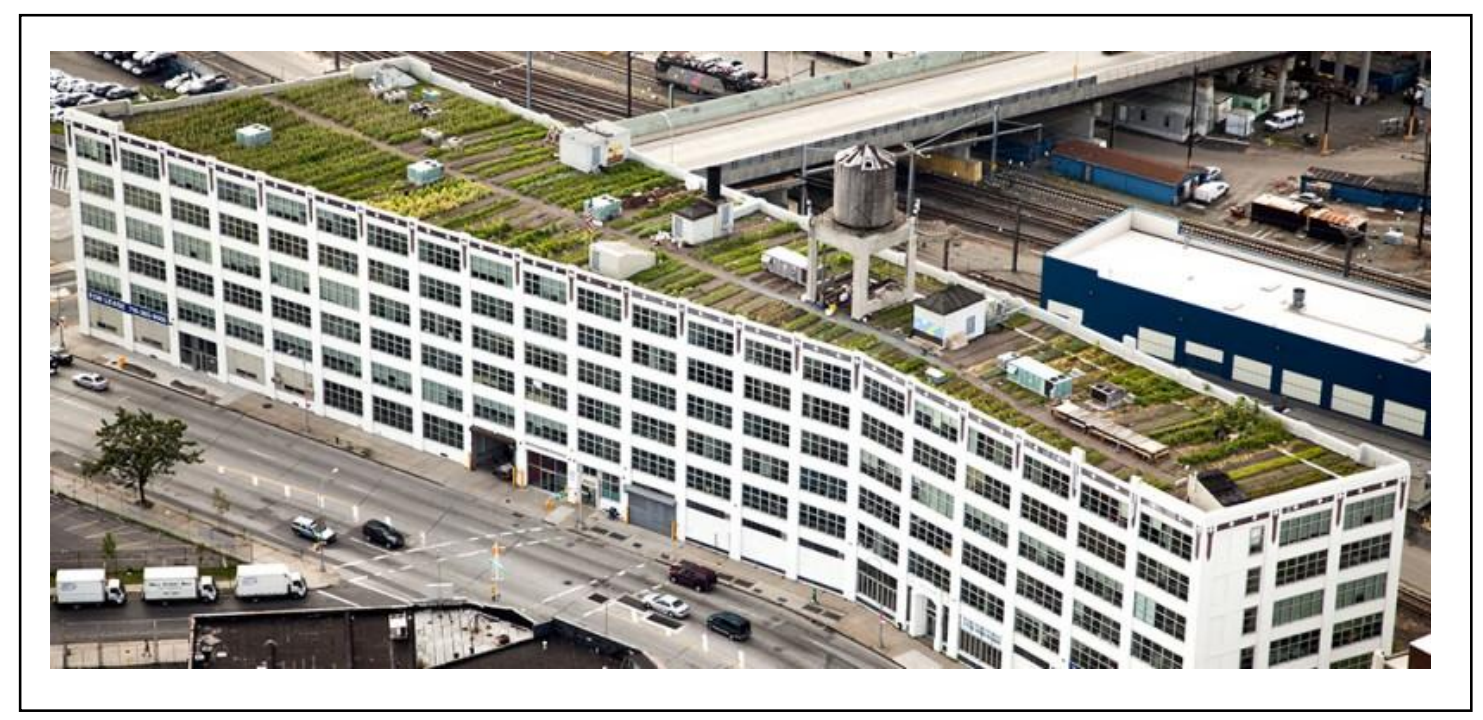

Fonte: Brooklyn Grange (2016).

A Brooklyn Grange Farm se posiciona mais do que apenas uma grande fazenda urbana, mas como uma concentração de serviços que atende a um mercado sustentável. As atividades incluem programa de treinamento agrícola, visitas, retiros corporativos, espaço para eventos diversos.

Embora haja uma grande diversificação de atividades, as quais diferem das de uma fazenda, a Brooklyn Grange Farm se coloca como uma fazenda de cultivo de alimentos nutritivos e saborosos. Sua preocupação com o uso adequado dos recursos naturais está inserida e explicitada em diversas partes de seu site institucional.

Fazer isso em Nova York é o nosso sonho. Acreditamos que esta cidade pode ser mais sustentável; que o nosso ar pode ser mais frio e cursos de água podem ser mais limpos. Acreditamos que os $14 \%$ dos nossos aterros compostos de restos de alimentos devem ser convertidos em energia orgânica para nossas plantas e plantas ao redor da cidade por meio de programas de compostagem ativos. Acreditamos que os alimentos devem ser frescos [...]. Porque, no final do dia, o que conta é estar com nossa família, admirando o pôr-do-sol sobre o horizonte da cidade, e comendo alimentos saudáveis [...] e lembrando-se: isto é que é comida de verdade (BROOKLYN GRANGE FARM, 2015, tradução da autora).

A Brooklyn Grange é uma fazenda urbana de cunho comercial, ou seja, o intuito de sua produção agrícola é voltado para a venda de seus produtos em um mercado específico. "Queremos que a agricultura se torne uma indústria próspera e viável nas cidades, e 
acreditamos que, praticando a agricultura urbana como uma empresa fiscalmente sustentável, podemos provar que isso é digno de investimento - tradução da autora (BROOKLYN GRANGE FARM, 2015). A fazenda é financiada por meio de sistema de equidade privada, empréstimos, eventos para angariar fundos econômicos e plataformas de crowdfunding $^{8}$ (como a Kickstarter.com).

Em vista disso, percebe-se a criação de novos mercados centrados na sustentabilidade ambiental e também na produção agrícola, como é o caso da agricultura urbana. A própria forma como o negócio das fazendas urbanas se mantém parte igualmente de maneiras inovadoras, que utilizam certo hibridismo de opções, como é o caso, por exemplo, da plataforma urbana crowfunding, aplicada à produção do meio rural. Neste sentido, há uma sobreposição de dois meios (urbano e rural), na qual há certa complementaridade. A própria nomenclatura, agricultura urbana, já pressupõe essa justaposição de conceitos permeada por um nicho de mercado.

As preocupações nesse tipo de agricultura voltada à produção nas cidades tornam-se mais complexas, agregando novas variáveis, que utilizam a tecnologia para solucionar os problemas que vão surgindo com o passar do tempo, conforme salientam Assis e Romeiro (2002). A agroecologia tem um papel estratégico e crucial neste novo formato de pensar o rural e o urbano, assim como uma produção de alimentos na área urbana. Entretanto, a agroecologia não se submete às regras do capital, como já mencionado por Caporal e Costabeber (2004).

Todavia, a lógica do mercado capitalista utiliza erroneamente a agroecologia como sinônimo de discursos sustentáveis e da viabilização de produção de alimentos orgânicos. Por esse ângulo, o marketing também assume uma posição relevante, reforçando a visão de Kotler (1998), Cobra (1992) e Giglio (1996) sobre as estratégias que elabora, conforme o mercado que articula. Tem-se em vista que, no caso da agricultura urbana, é o setor do marketing que irá fortalecer e posicionar esse tipo de agricultura feita em um espaço

\footnotetext{
${ }^{8}$ É um financiamento coletivo, que consiste na obtenção de capital para iniciativas de interesse coletivo, através da agregação de múltiplas fontes de financiamento, em geral, pessoas físicas interessadas na iniciativa proposta. O termo é, muitas vezes, usado para descrever especificamente ações na Internet com o objetivo de arrecadar dinheiro para artistas, pequenos negócios e start-ups, filantropia e ajudar as regiões atingidas por desastres, entre outros.
}

COLÓQUIO - Revista do Desenvolvimento Regional - Faccat - Taquara/RS - v. 15, n. 1, jan./jun. 2018 
urbano, assim como também fará a associação entre a agroecologia e a sua relação com o consumidor.

Ao mesmo tempo, verifica-se que é uma oportunidade para a agroecologia utilizar as ferramentas de que dispõe na contemporaneidade (e, nesse caso em particular, o próprio marketing) para elucidar sua verdadeira essência e prática. Mesmo a agroecologia não seguindo a lógica do capital e nem uma demanda particular do mercado, conforme salientou Candioto, Carrijo e Oliveira (2008) e também Caporal e Costabeber (2004), o mercado pode se adequar ao formato da agroecologia, levando, nesse sentido, a uma compreensão mais clara da importância das relações estabelecidas no agroecossistema de forma conjunta. Se os mercados são criados a partir de uma demanda dos consumidores, há, na contemporaneidade, não só uma busca por um consumo sustentável, mas também por uma consciência agroecológica ancorada em bases sustentáveis. A agroecologia não é um negócio, mas é utilizada, de certa forma, pelos grandes produtores como parte de seus discursos sustentáveis e de seus negócios, o que explicaria os motivos de tantas interpretações difusas sobre o tema.

Todavia, o panorama que se apresenta evidencia não apenas novos pensamentos sobre o urbano e o rural, mas a busca por uma qualidade de vida melhor fundamentada por um estilo de vida sustentável. Nessa perspectiva, a agroecologia tem um papel estratégico neste movimento entre rural e urbano, práticas sustentáveis e demanda de mercado.

\section{Considerações finais}

A busca por uma maior qualidade de vida é um estilo que vem ganhando cada vez mais adeptos, tendo a agroecologia um papel relevante nesse movimento em que se sobrepõem rural e urbano. Não se pode mais pensar em uma dicotomia entre esses dois ambientes, mas em uma integração e complementariedade que os une mais do que os separa. Com a reconfiguração dos espaços urbanos vazios e a sobreposição do rural e do urbano, novas relações irão se estabelecer, tendo a agroecologia um papel estratégico e relevante a firmar.

A agricultura urbana se mostra como mais uma alternativa viável para um futuro sustentável das cidades e para sua própria resiliência, não ficando somente no campo a COLÓQUIO - Revista do Desenvolvimento Regional - Faccat - Taquara/RS - v. 15, n. 1, jan./jun. 2018 
pressão por produção de alimentos. Também é uma forma de repensar o uso excessivo dos recursos naturais e a reutilização de espaços vazios na cidade. Embora o mercado faça pressão por uma demanda de alimentos, percebe-se que esta é também uma oportunidade para a agroecologia esclarecer melhor suas práticas sustentáveis, desfazendo as más interpretações que possui na contemporaneidade.

De forma geral, o ser humano vem, ao longo do tempo, tentando compreender melhor sua relação com o meio ambiente. Essas tentativas levam à busca de soluções alternativas para seus problemas conforme eles vão surgindo. Ao tomarem consciência dos processos mais sustentáveis, as pessoas podem escolher o que consumir, ao mesmo tempo em que orientam o mercado às práticas mais sustentáveis. Nestas escolhas, todos saem ganhando: pessoas e recursos naturais. Destarte, a agroecologia e o consumidor consciente têm papéis importantes e estratégicos neste ciclo de novos mercados sustentáveis na busca por um mundo melhor.

O ser humano vive em um momento no qual não se pode mais pensar de forma isolada. Há necessidade de se pensar em alternativas mais sustentáveis para o uso dos recursos disponíveis no meio ambiente, que, cada vez mais, ficam escassos. Nesse sentido, uma das possibilidades pode ser a agroecologia em cidades, com a utilização dos espaços urbanos para a produção de alimentos. No entanto, questiona-se se realmente esses espaços estão sendo utilizados para a produção de alimentos a partir de uma lógica mais consciente dos recursos naturais escassos, ou se constituem apenas uma reprodução capitalista que usa esses mesmos espaços a partir de uma tendência mundial de novo(s) mercado(s).

\section{Referências}

ASSIS, Renato, L. de; ROMEIRO, Ademar R. Agroecologia e agricultura orgânica: controvérsias e tendências In: BRANDENBURG, Alfio (Org.). Desenvolvimento e Meio Ambiente: caminhos da agricultura ecológica. Curitiba: UFPR, 2002. p. 67-80. 
BEDANTE, Gabriel. Navarro. A influência da consciência ambiental e das atitudes em relação ao consumo sustentável na intenção de compra de produtos ecologicamente embalados. Dissertação de Mestrado apresentada a Universidade Federal do Rio Grande do Sul. 2004. Disponível em: <http://www.lume.ufrgs.br/bitstream/handle/10183/3904/0004505 35. pdf?sequence=1>. Acesso em: 5 set. 2015.

BROOKLYN GRANGE. Fazenda urbana Brooklyn Grange Farm, de Nova York. Site institucional. Disponível em <http://brooklyngrangefarm.com>. Acesso em: 7 set. 2015.

CBCS. Conselho Brasileiro de Construção Sustentável. Site institucional. Disponível em: <http://www.cbcs.org.br/website/>. Acesso em: 5 set. 2015.

CANDIOTTO, CARRIJO E OLIVEIRA. A Agroecologia e as agroflorestas no contexto de uma Agricultura Sustentável. In: ALVES, A. F.; CARRIJO, B. R.; CANDIOTTO, L. Z. P. (Org.). Território e Desenvolvimento Sustentável. São Paulo: Expressão Popular, p. 213-232, 2009.

CAPORAL, Francisco Roberto; COSTABEBER, José Antônio. Agroecologia: alguns conceitos e princípios. Brasília: MDA/SAF/DATER-IICA, 2004. Disponível em:

<http://www.planetaorganico.com.br/trabCaporalCostabeber.htm>. Acesso em: 25 ago. 2015.

COBRA, Marcos. Administração de marketing. 2. ed. São Paulo: Atlas, 1992.

DE TONI, Deonir et al. Desenvolvimento e Meio Ambiente, v. 28, jul./dez., p. 173-188, 2013. Disponível em: <http://revistas.ufpr.br/made/article/view/31003/21667>.

Acesso em: 15 jan. 2016.

FAO. Agricultura Urbana e Periurbana na América Latina e No Caribe: uma realidade. Disponível em <http://www.agriculturaurbana.org.br/sitio/textos/FUM\%20IPES_FAO.pdf>. Acesso em: set. 2015a.

FAO. Organização da ONU para a Alimentação e a Agricultura. Site Institucional. Disponível em: <https://www.fao.org.br/>. Acesso em: set. 2015b.

GIGLIO, Ernesto. O comportamento do Consumidor e a gerência de marketing. São Paulo: Pioneira, 1996.

KOTLER, Philip. Administração de marketing: análise, planejamento, implementação e Controle. São Paulo: Atlas,1998.

RUAF. Fundação de Agricultura Urbana. Site Institucional. Disponível em <http://www.ruaf.org/>. Acesso em: set. 2015.

INSTITUTO CIDADE JARDIM. Site Institucional. Disponível em <https://institutocidadejardim.wordpress.com/2011/02/28/o-que-sao-telhados-verdes/>. Acesso em: set. 2015. 
MOUGEOT, Luc J. A. Agricultura Urbana: conceito e definição. Revista deAgricultura Urbana, n. 1, dez. 2005. Disponível em: <http://www.ruaf.org/sites/default/files/ AU1conceito.pdf>. Acesso em: set. 2015.

MUELLER, Charles. Os economistas e as relações entre o sistema econômico e o meio ambiente. Brasília: Universidade Brasília, 2007.

NIEDERLE, Paulo André; ALMEIDA, Luciano de; VEZZANI, Fabiane Machado. Agroecologia: práticas, mercados e políticas para uma nova agricultura. Curitiba: Kairós, 2013.

SPOSITO, Maria E. B. A questão campo-cidade: perspectivas a partir da cidade. In: SPOSITO, Maria E. B. (Org.) Cidade e campo: relações e contradições entre o urbano e o rural. São Paulo: Expressão Popular, 2006. p. 111-130. 